Article

\title{
Study of the Selectivity and Bioactivity of Polyphenols Using Infrared Assisted Extraction from Apricot Pomace Compared to Conventional Methods
}

\author{
Dina Cheaib ${ }^{1}$, Nada El Darra ${ }^{2,+}{ }^{+}$, Hiba N. Rajha ${ }^{3,+}{ }^{,}$Iman El-Ghazzawi ${ }^{2}$, \\ Youssef Mouneimne ${ }^{4}$, Adla Jammoul ${ }^{5}$, Richard G. Maroun ${ }^{3, *(D)}$ and Nicolas Louka ${ }^{3}$ \\ 1 Faculty of Sciences, Beirut Arab University, P.O. Box 115020, Riad El Solh, Beirut 1107 2809, Lebanon; \\ dac273@student.bau.edu.lb \\ 2 Faculty of Heath Sciences, Beirut Arab University, Tarik El Jedidah-Beirut, P.O. Box 115020, Riad EL Solh, \\ Beirut 1107 2809, Lebanon; n.aldarra@bau.edu.lb (N.E.D.); i.ghazzawi@bau.edu.lb (I.E.-G.) \\ 3 Research Unit of Agro-Food Technologies and Valorization, Analysis and Research Center, Faculty of \\ Sciences, Saint-Joseph University of Beirut, B.P. 11-514 Riad El Solh, Beirut 1107 2050, Lebanon; \\ hiba.rajha@usj.edu.lb (H.N.R.); nicolas.louka@usj.edu.lb (N.L.) \\ 4 K.A.S. Central Research Science Laboratory, Department of Research Science Laboratory, American \\ University of Beirut, P.O. Box 11-0236, Beirut, Lebanon; ym01@aub.edu.lb \\ 5 Food Department, Lebanese Agricultural Research Institute, Fanar, Lebanon; ajammoul@lari.gov.lb \\ * Correspondence: richard.maroun@usj.edu.lb \\ + Those authors contributed equally.
}

Received: 23 October 2018; Accepted: 23 November 2018; Published: 27 November 2018

\begin{abstract}
The valorization of industrial food byproducts by means of environment-friendly extraction methods is becoming a major interest because of its environmental and economic values. In this study, the efficiency of many technologies, such as ultrasounds (US), microwaves (MW), and infrared (IR), was compared, in terms of polyphenol yield and bioactivity from apricot pomace. IR was the most effective method with the highest polyphenol (10 mg GAE/g DM), flavonoid (6 mg CE/g DM), and tannin $(3.6 \mathrm{mg} / \mathrm{L})$ yields. In terms of efficacy, IR was followed by MW, US, then solid-liquid (S/L) extraction. IR extract from apricot pomace exhibited the highest inhibitory activity against all the studied gram-positive strains (Methicillin Resistant Staphylococcus aureus, Staphylococcus aureus, Methicillin-resistant Staphylococcus epidermidis, and Staphylococcus epidermidis) and a one gram-negative strain (Escherichia coli). Moreover, IR extracts had by far the highest antiradical activity (AC) $(40 \%)$ followed by MW (31\%), US (28\%), and then S/L (15\%). High-performance liquid chromatography (HPLC) permitted the identification and quantification of rutin in all extracts; whereas catechin was

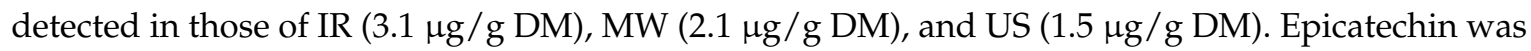
exclusively found in IR extract $(4 \mu \mathrm{g} / \mathrm{g}$ DM), suggesting the selectivity of IR towards this compound. Scanning electron microscopy (SEM) revealed that the IR technique induced the highest cellular and structural damage in apricot pomace, which could explain the effectiveness of this technology.
\end{abstract}

Keywords: apricot pomace; polyphenols; infrared; microwaves; ultrasounds

\section{Introduction}

Nowadays, the valorization of fruit byproducts has become of great interest due to their content in several bioactive molecules, such as polyphenols. Different methods have been used for the recovery of polyphenols from different matrices. Solid/liquid (S/L) extraction is the conventional process adopted in many industries for polyphenol recuperation. However, one of its main disadvantages is the massive consumption of organic solvents. The latter present a significant cost for the manufacturing. Organic 
solvent use in food processing is, therefore, not recommended [1]. The main research focus in recent years is the use of eco-friendly technologies that diminish organic solvent use and energy consumption. Many studies were, therefore, conducted on polyphenol recovery from different byproducts by means of emerging technologies, such as high-voltage electrical discharges (HVED), pulsed electric fields (PEF), infrared (IR), ultrasounds (US), and microwave-assisted extractions. The action mechanism of every technique is involved in the efficacy of polyphenol extraction. For example, the efficiency of ultrasounds, which are sound waves, is related to the mechanical vibrations they produce in the solid, thus having the ability to provoke structural damage and therefore enhance the extraction process of intracellular components (polyphenols, essential oils, etc.) [2]. Compared to conventional methods, US is considered as an effective operation that increases mass transfer, and reduces time and solvent consumption. For example, this technique has been found to improve the extraction yield of polyphenols ranging from $11 \%$ to $35 \%$ compared to the conventional method (solid-liquid extraction) from red grape marc [3]. Microwaves are electromagnetic radiations in the frequency between $300 \mathrm{MHz}$ and $300 \mathrm{GHz}$. The microwave energy transformation to heat is caused by ionic conduction and dipole rotation, and leads to an increased solubility of the molecules of interest (such as polyphenols) in the solvent [4]. Microwave technology is a simple, time-saving method that reduces solvent consumption and energy cost. Compared to ultrasonic extraction, the microwave technique gave higher polyphenol extraction (up to four-fold) from different spices (Cinnamomum zeylanicum, Coriandrum sativum, Cuminum cyminum, and Crocus sativus) $[5,6]$.

Infrared-assisted extraction (IRAE) technique, used as the heat source, is composed of an infrared lamp. Its highest efficiency is attributed to its high capacity of penetration [7]. Compared to other traditional extraction techniques, infrared is cheap, easy, and free of radiation, and could improve the extraction of many bioactive compounds from plants. The infrared extraction of polyphenols from rice hull showed an increase from 0.12 to $0.19 \mathrm{mM}$ after $30 \mathrm{~min}$ and an improved the antioxidant activity from $47 \%$ to $79 \%$ compared to solid-liquid ones [8].

To the best of our knowledge, no study was yet conducted on infrared, microwave, and ultrasound-assisted extraction of polyphenols from apricot pomace. The main objective of this study was to compare the selectivity and efficiency of infrared assisted extraction on the enhancement of polyphenol recovery from apricot pomace compared to conventional techniques: Microwave, ultrasound-assisted extraction, and the solid-liquid method. The second objective was to assess their impact on biological activities (antiradical and antimicrobial activity).

\section{Materials and Methods}

\subsection{Raw Materials}

Apricot pomace (consisting of pressed skins and pulp residues) used in this study were obtained from Conserves Modernes Chtaura, Lebanon.

\subsection{Extraction Experiments}

The extraction experiments were conducted at different times to reach the same energy consumption of $2290.90 \mathrm{~kJ} / \mathrm{kg}$ for IR, MW, US, and S/L.

\subsubsection{Infrared-Assisted Extraction}

The infrared-assisted extraction set-up was designed by the Faculté des Sciences, Université Saint Joseph de Beyrouth (Figure 1d). The extraction prototype consists of a ceramic infrared transmitter (power ranging from 63 and $170 \mathrm{~W}$ ) for the heating process, linked to a proportional-integral-derivative (PID) control, where the temperature and voltage are adjusted automatically or manually. This novel method uses infrared energy emitted from the ceramic transmitter to heat the solvent matrix mixture contained in a round bottom flask and placed at a changeable distance away from the ceramic transmitter. To a round-bottom flask, $100 \mathrm{~mL}$ of preheated water $\left(75^{\circ} \mathrm{C}\right)$ and $10 \mathrm{~g}$ of apricot pomace 
was added. The flask was then fixed on the top of the ceramic transmitter. The temperature was set at $75{ }^{\circ} \mathrm{C}$ for $60 \mathrm{~min}$ (based on a preliminary study). Please note that some of the apricot pomace will dissolve, but most will be insoluble in water. The specific IR energy $W_{I R}(\mathrm{~kJ} / \mathrm{kg})$ was calculated using:

$$
W_{I R}=\frac{P_{I R} \times t_{I R}}{m}
$$

where $P$ is the generator power $(70 \mathrm{~J} / \mathrm{s}), t$ is the total treatment duration $(\mathrm{s}), m$ is the product mass $(\mathrm{kg})$, noting that $m=110 \mathrm{~g}$ (100 $\mathrm{g}$ water $+10 \mathrm{~g}$ of apricot pomace), and $W$ is the energy consumed $(2290.90 \mathrm{~kJ} / \mathrm{kg})$.

a)

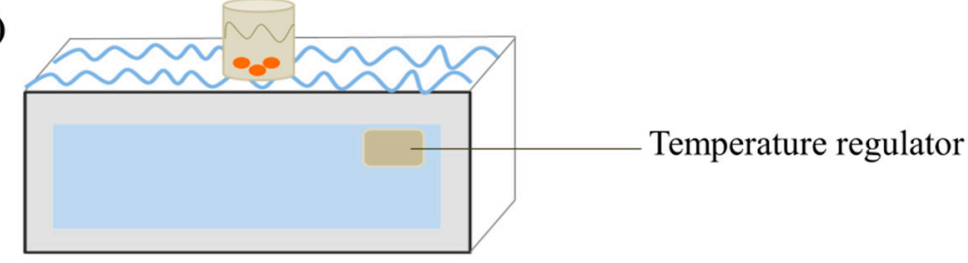

b)

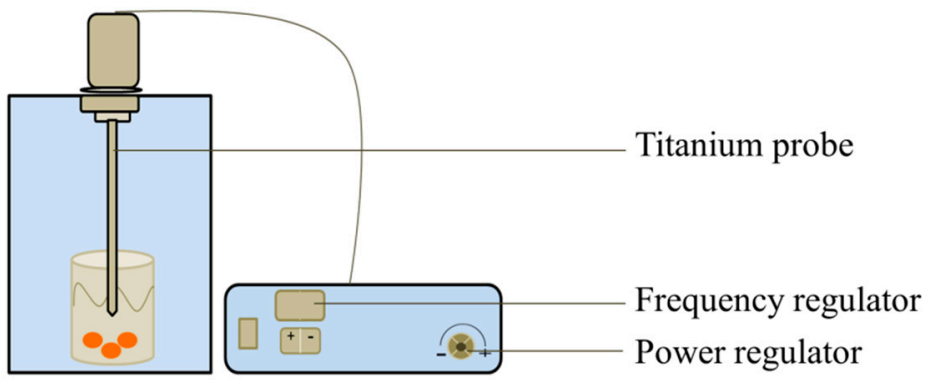

c)

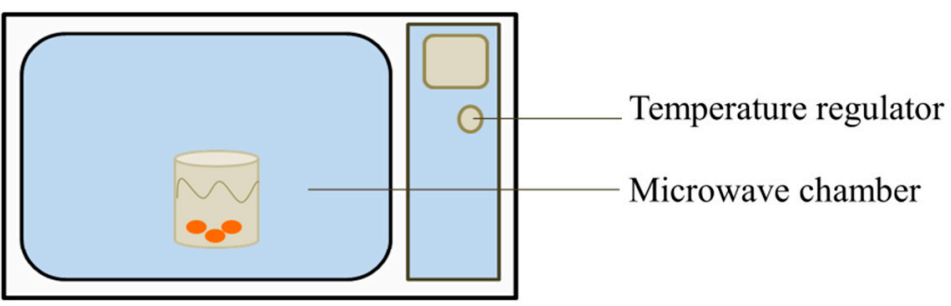

d)

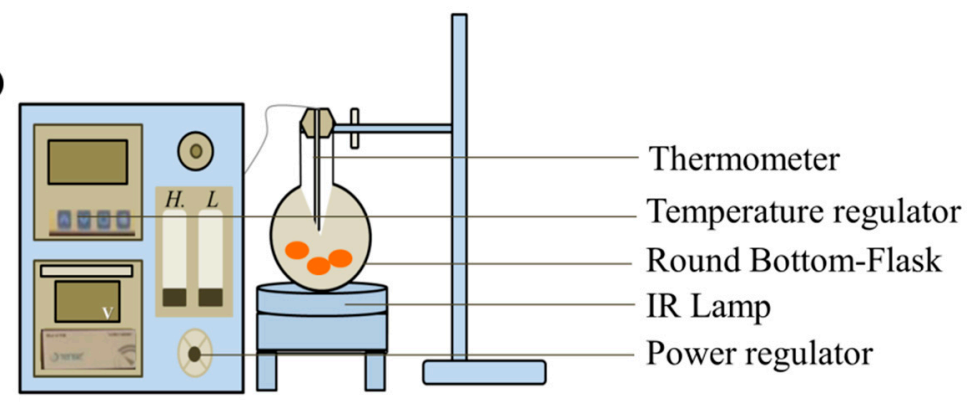

Figure 1. Instrumental set-up for the (a) solid-liquid, (b) ultrasound, (c) microwave, and (d) infrared methods.

\subsubsection{Solid-Liquid Extraction}

The solid-liquid extraction process was conducted by using a water bath (power of $660 \mathrm{~W}$ ) (Figure 1a). $100 \mathrm{~mL}$ of preheated water $\left(75^{\circ} \mathrm{C}\right)$ was mixed with $10 \mathrm{~g}$ of apricot pomace in a glass flask. The temperature in the water bath was set at $75^{\circ} \mathrm{C}$. 
The time needed for the solid-liquid extraction, $t_{S / L}(s)$, to reach the energy required $(2290.90 \mathrm{~kJ} / \mathrm{kg})$ was calculated as follows:

$$
t_{S / L}=\frac{W_{S / L} \times m}{P_{S / L}}
$$

where $W$ is the energy consumed $(2290.90 \mathrm{~kJ} / \mathrm{kg}), P$ is the generator power $(660 \mathrm{~J} / \mathrm{s}), m$ is the product mass $(\mathrm{kg})$, and $t$ is the total treatment duration (s).

\subsubsection{Ultrasound Extraction}

The ultrasound apparatus (BANDELIN SONOPLUS, HD 2200, Berlin, Germany) (Figure 1b) was composed of an ultrasonic generator (maximum power of $200 \mathrm{~W}$ and a maximum frequency of $24 \mathrm{kHz}$ ) coupled to a titanium probe placed in a chamber. The probe was immersed in a glass flask containing $10 \mathrm{~g}$ of apricot pomace mixed with $100 \mathrm{~mL}$ of preheated water $\left(75^{\circ} \mathrm{C}\right)$. To avoid heating during the US extraction, the temperature of the mixture was controlled by placing the flask in a cold water bath.

The US energy was calculated as follows:

$$
W_{U S}=\frac{P_{U S} \times t_{U S}}{m}
$$

where $W$ is the energy consumed $(2290.90 \mathrm{~kJ} / \mathrm{kg}), P$ is the generator power $(200 \mathrm{~J} / \mathrm{s}), m$ is the product mass $(\mathrm{kg})$, and $t$ is the total treatment duration (s).

\subsubsection{Microwave Extraction}

The microwave used in this experiment is a traditional one (Kenwood, MW 572, Kanagawa, Japan) (Figure 1c) with a power of $900 \mathrm{~W}$. The mixture containing $10 \mathrm{~g}$ of apricot pomace mixed in $100 \mathrm{~mL}$ of preheated water at $75^{\circ} \mathrm{C}$ was placed inside the microwave chamber.

The MW energy was calculated as follows:

$$
W_{M W}=\frac{P_{M W} \times t_{M W}}{m}
$$

where $W$ is the energy consumed $(2290.90 \mathrm{~kJ} / \mathrm{kg}), P$ is the microwave power $(900 \mathrm{~J} / \mathrm{s}), m$ is the product mass $(\mathrm{kg})$, and $t$ is the total treatment duration (s).

\subsection{Analysis}

\subsubsection{Dry Matter Content}

For the calculation of the dry matter content of the raw material, an appropriate amount $(10 \mathrm{~g})$ of sample was weighed and then dried for $24 \mathrm{~h}$ in a ventilated oven at $105^{\circ} \mathrm{C}$ [9].

\subsubsection{Quantification of Total Polyphenol Content by the Folin-Ciocalteu Method}

The quantification of the total polyphenols was done by mixing $0.2 \mathrm{~mL}$ of the apricot pomace extract, $0.1 \mathrm{~mL}$ of $\mathrm{FC}$ reagent, and $0.8 \mathrm{~mL}$ of sodium carbonate $\mathrm{Na}_{2} \mathrm{CO}_{3}(75 \mathrm{mg} / \mathrm{L})$, and was then incubated at $60^{\circ} \mathrm{C}$ for $10 \mathrm{~min}$. The color generated was measured at $750 \mathrm{~nm}$ using a spectrophotometer UV-VIS (Gold S54T UV-VIS, Shanghai, China). The polyphenol concentration of the samples was evaluated compared to a calibration curve of gallic acid and determined as milligrams of gallic acid equivalent (GAE) per gram of dry matter of pomace (DM) (mg GAE/g DM) [10].

\subsubsection{Determination of the Antiradical Activity}

The scavenging activity of DPPH free radical was examined by the DPPH (1,1-diphenyl-2-picrylhydrazyl) scavenging method. $4 \mathrm{~mL}$ of $0.1 \mathrm{mM} \mathrm{DPPH}$ (dissolve in methanol) 
were mixed with $0.2 \mathrm{~mL}$ of the extracts and then kept at room temperature for $30 \mathrm{~min}$. The reduction of the DPPH free radical was examined by reading the absorbance at $517 \mathrm{~nm}$ [11]. Methanol was used as a blank. Two models were represented; the percentage of inhibition at the initial concentration of the extracts and the inhibition percentage at a fixed polyphenol concentration (4 mg GAE/g DM) in order to test the influence of their diversity. The inhibition percentage of the DPPH free radical was calculated as follows:

$$
\% \text { inhibition }=\left[\frac{(\text { absorbance of control }- \text { absorbance of test sample })}{\text { absorbance of control }}\right] \times 100
$$

\subsubsection{Determination of Tannin Concentration}

The determination of tannin content was determined to the method reported by Ribéreau-Gayon et al. Two tubes were prepared, each one containing $1 \mathrm{~mL}$ of the extract, $0.5 \mathrm{~mL}$ of water, and $1.5 \mathrm{~mL}$ of hydrogen chloride $\mathrm{HCl}(12 \mathrm{~N})$. The first tube was heated at $100{ }^{\circ} \mathrm{C}$ for $30 \mathrm{~min}$ and the second one was kept at room temperature for the same duration. Then, $0.25 \mathrm{~mL}$ of ethanol was added after the rapid cooling of each tube and the absorbance was measured at $520 \mathrm{~nm}$ [12]. The tannin concentration was calculated as follows:

$$
\text { Tannin concentration }\left(\frac{m g}{L}\right)=19.33 \times \Delta \text { optical densities }
$$

\subsubsection{Determination of Total Flavonoids (TF)}

The total flavonoids content was analyzed by mixing $1 \mathrm{~mL}$ of apricot sample extract and $4 \mathrm{~mL}$ of water. After $5 \mathrm{~min}, 0.3 \mathrm{~mL}$ of sodium nitrite $\mathrm{NaNO}_{2}(5 \%)$ and $1.5 \mathrm{~mL}$ of aluminium chloride $\mathrm{AlCl}_{3}$ $(2 \%)$ were added. $2 \mathrm{~mL}$ of sodium hydroxide $\mathrm{NaOH}(1 \mathrm{M})$ was then added to the mixture solution after a brief incubation at room temperature for $5 \mathrm{~min}$. The color generated was read at $510 \mathrm{~nm}$. Total flavonoids content in samples was analyzed using the calibration curve of catechin and expressed as the $\mathrm{mg}$ of catechin equivalent (CE) per g of dry matter [13].

\subsubsection{HPLC-DAD Analysis}

The polyphenol analyses of the extracts prepared from the apricot pomace were determined using high-performance liquid chromatography (HPLC). The apparatus consisted of a liquid-chromatography-Agilent 1100 Series system (Teknokroma Professional Friendly Lichrospher $100 \mathrm{RP} 185 \mu \mathrm{M}, 25 \times 0.46$, Serial number NF-21378, Barcelona, Spain), an autosampler, a column oven, and a diode array detector. The separation and identification of the polyphenolic molecules was done using a C18 Column Zorbax (Barcelona, Spain) $(25 \times 0.46 \mathrm{~mm})$. The volume injected was $10 \mu \mathrm{L}$ and the flow rate was of $1 \mathrm{~mL} / \mathrm{min}$. The chromatographic conditions consisted of a mobile phase made up of acidified nanopure water at $\mathrm{pH} 2.3$ with $\mathrm{HCl}(\mathrm{A})$ and acetonitrile (B). The elution was performed using isocratic conditions as follows: From 0 to 5 min with $(85 \%)$ A and (15\%) B. Gradient profile ranged from 5 to $30 \mathrm{~min}$, beginning with (85\%) A and (15\%) B and ending with ( $0 \%$ ) A and $(100 \%)$ B. Isocratic conditions from 30 to 35 min with $(0 \%)$ A and (100\%) B were then done. Each compound was identified by comparing different retention times of each peak to those of the standards ones [14]. The quantification of the phenolic molecules was evaluated using the standard curve determined for each molecule by injecting various concentration of each standard: Epicatechin, catechin, and rutin.

\subsubsection{Bacterial Strains, Culture Media, and Growth Conditions}

The antibacterial activity was screened against eight different bacterial strains: Two strains of Staphylococcus epidermidis, amongst which, one is Methicillin resistant (MRSE 2380); two gram positive bacterial strains of Staphylococcus aureus, amongst which, one is methicillin-resistant staphylococcus aureus (MRSA 2); two gram negative strains of Klebsiella pneumonia, amongst 
which, one is Metallo-beta-lactamase producer; and two strains of Escherichia coli strains amongst which, one is extended spectrum beta lactamase (ESBL 2238).

\subsubsection{Preparation of the Bacterial Inocula for Minimal Inhibitory Concentration (MIC)}

The bacterial strains were cultured on a freshly-prepared blood agar. Part of the colonies of each bacterial strain was inoculated in $3 \mathrm{~mL}$ of cation adjusted Mueller Hinton broth until reaching a turbidity of $0.5 \mathrm{McF}$ arland. Then, a dilution of $1 / 100$ was made into tubes of adjusted Mueller Hinton broth [15].

\subsubsection{Phenolic Extracts Preparation for MIC Assessment}

The minimal inhibitory concentration assessment was done for each infrared, microwave, ultrasound, and solid-liquid extracts using five serial dilutions (starting from 2.5 to $40 \mu \mathrm{g} / \mathrm{mL}$ ). Using $0.4 \mu \mathrm{m}$ disposable syringe filters, all stocks were sterilized. The concentrations of the four different polyphenolic extracts were diminished to: $20 \mu \mathrm{g} / \mathrm{mL}$ and up to $1.25 \mu \mathrm{g} / \mathrm{mL}$ after adding equal volumes $(100 \mu \mathrm{L})$ of the four apricot extracts to the different bacterial strains $(100 \mu \mathrm{L})$ using 96 well (U shape) microtiter plates. After an overnight incubation at $37^{\circ} \mathrm{C}$, the microtiter plates of each polyphenolic extract were read in order to determine the MIC that blocks the bacterial growth.

\subsection{Scanning Electron Microscopy (SEM)}

The microstructure of the apricot pomace cells was investigated after extraction. Cells were first lyophilized at $-55{ }^{\circ} \mathrm{C}$ (Ilshin Lab. Co. Ltd., Yangju-si, Korea). A conductive double layer carbon support coating and then gold coating (Quorum 150T ES, London, UK) was applied to the cells. Samples were then examined by scanning electron microscopy (SEM) (TESCAN MIRA3 FEG-SEM, Prague, Czech Republic) with a high vacuum voltage.

\subsection{Statistical Analysis}

Each experiment was repeated twice. The standard deviations and means were calculated. The standard errors correspond to the error bars in all figures. The Least Significant Difference test (LSD) as well as variance analyses (ANOVA) were calculated in order to determine the significant differences. The statistical analyses were carried out using STATGRAPHICS ${ }^{\circledR}$ Centurion XV software (StatPoint Technologies, Inc., Warrenton, VA, USA).

\section{Results and Discussion}

\subsection{Effect of Different Extraction Techniques on Polyphenols, Tannins, and Flavonoids Concentrations in Apricot Pomace Extracts}

Figure 2a presents the yield of polyphenols from apricot pomace, treated by different techniques (infrared, microwave, ultrasound, and solid-liquid extraction), as a function of the energy input. At the same energy $(2290 \mathrm{~kJ} / \mathrm{kg})$, the maximal polyphenol yield was obtained by infrared (IR) (10.8 mg GAE/g DM) followed by microwave (MW) (5 mg GAE/g DM), ultrasound (US) (4.8 mg GAE/g $\mathrm{DM})$, and solid-liquid (S/L), which exhibited the lowest polyphenol yield (4 mg GAE/g DM). At the same treatment duration (e.g., $5 \mathrm{~min}$ ), IR also gave the highest polyphenol yield (5.3 $\mathrm{mg} \mathrm{GAE} / \mathrm{g}$ DM) compared to MW (5 mg GAE/g DM), US (4.3 mg GAE/g DM), and S/L (3.8 mg GAE/g DM). The efficiency of IR extraction can be attributed to the electromagnetic waves that excite the sample molecules in the modes of twisting, stretching, and bending $[8,16]$. In concordance with our results, Cai et al. (2011) showed that IR exhibited a higher extraction yield of procyanidin B2, catechin, and epicatechin from grape seeds compared to microwave-assisted extraction and ultrasounds [16]. The enhancement recovery using microwaves was attributed to its heating effect due to the rotation movement of the solvent inside the microwave chamber. This causes a rapid elevation of the solvent temperature, which increases the solubility of phenolic molecules [17]. Flavonoid and tannin recoveries 
for IR, MW, US, and S/L apricot pomace are presented in Figure 2b,c, respectively. In concordance with polyphenol content; IR was 1.5 and 2 times more efficient than US and MW in extracting flavonoids and tannins, respectively.

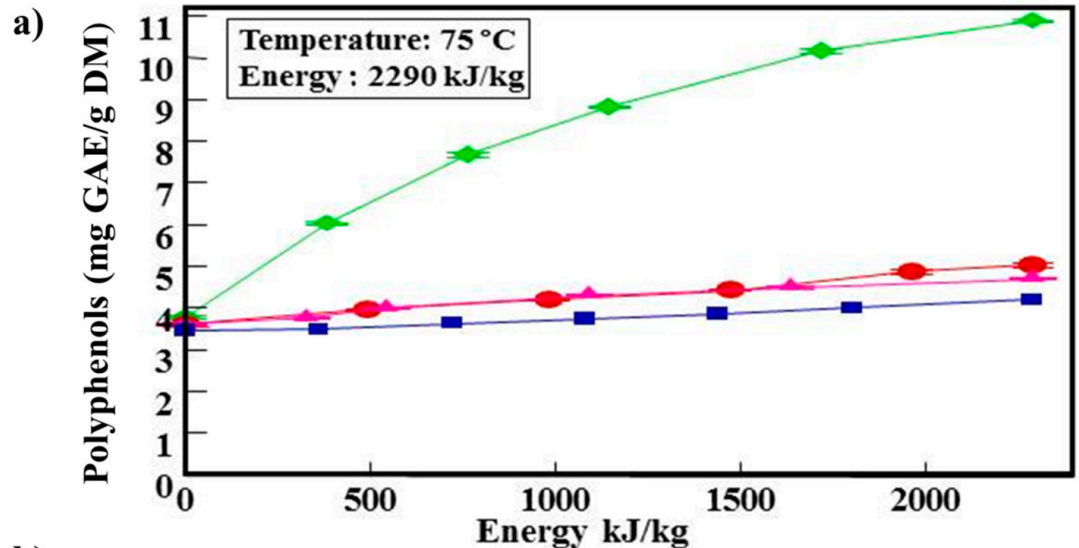

b)

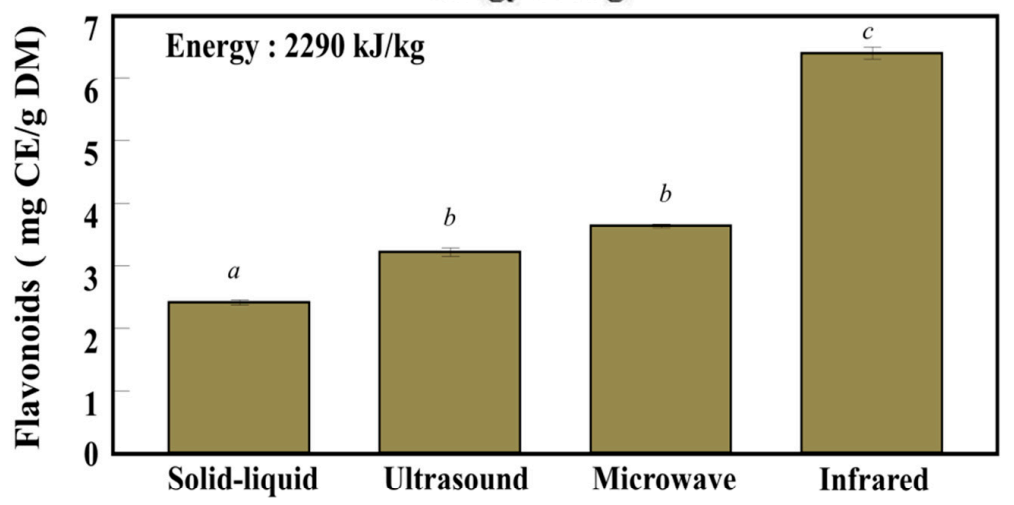

c)

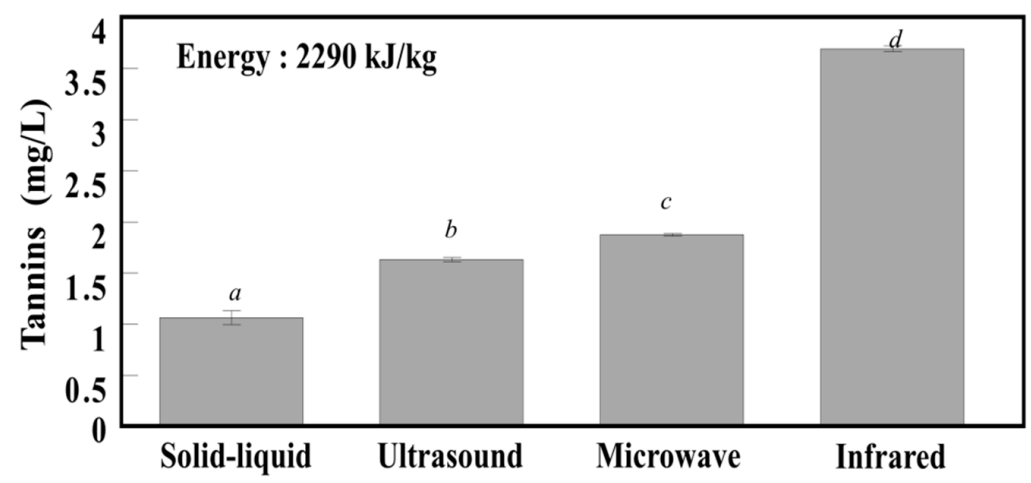

Figure 2. (a) Polyphenol yield of apricot pomace treated with $>$ infrared, microwave, ultrasound, and solid-liquid as a function of energy input. (b) Flavonoid and (c) tannin recovery for solid-liquid, ultrasound, microwave, and infrared of apricot pomace extracts. Different superscript letters indicate a significant statistical difference $(p<0.05)$.

Each technique plays an important role in the extraction process from the sample matrix. IR radiation directly heats the sample matrix without heating the surrounding air, which could increase in the extraction of bioactive molecules. However, in conventional methods, a longer time is needed before the energy of heat is conducted and transferred to the sample matrix [16]. The effectiveness of the IR extraction method could be due to the matching between the absorption characteristics of the solvent used and the wavelength of the infrared heater [8]. 


\subsection{Scanning Electron Microscopy of the Apricot Pomace Extracted by Different Techniques}

The images of apricot pomace obtained by scanning electron microscope (SEM) prior to and after different treatments are shown in Figure 3. Compared to Figure 3a,b, which represented the intact cells of apricot pomace, solid/liquid (Figure 3c,d) showed partially damaged cells, followed by ultrasounds (Figure 3e,f) and microwaves (Figure 3g,h), which exhibited more ruptured cells. Infrared extraction (Figure 3i,j) showed the highest disrupted apricot pomace cells with a small presence of intact cells (shown in Figure 3j). The IR wave heating mechanism with its high efficiency was shown to result in high cell bursting [16]. The MW technique causes the rupture of cells because they are subjected to a localized pressure and thermal stress [18]. Concerning the US technique, the local pressure of the implosion air bubbles contributes to the damage of the proximate cellular membranes [19]. The SEM results are in concordance with the results obtained for polyphenol, flavonoid, and tannin, and indicate that the more ruptured and damaged the cells are, the more polyphenols are extracted.
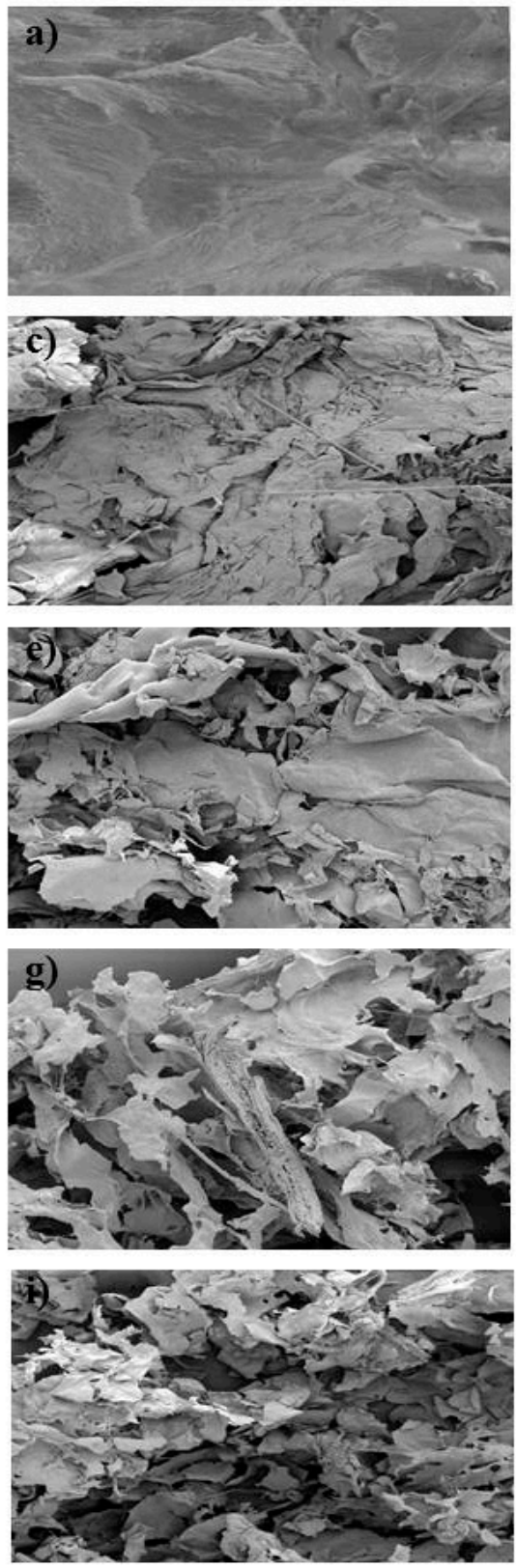
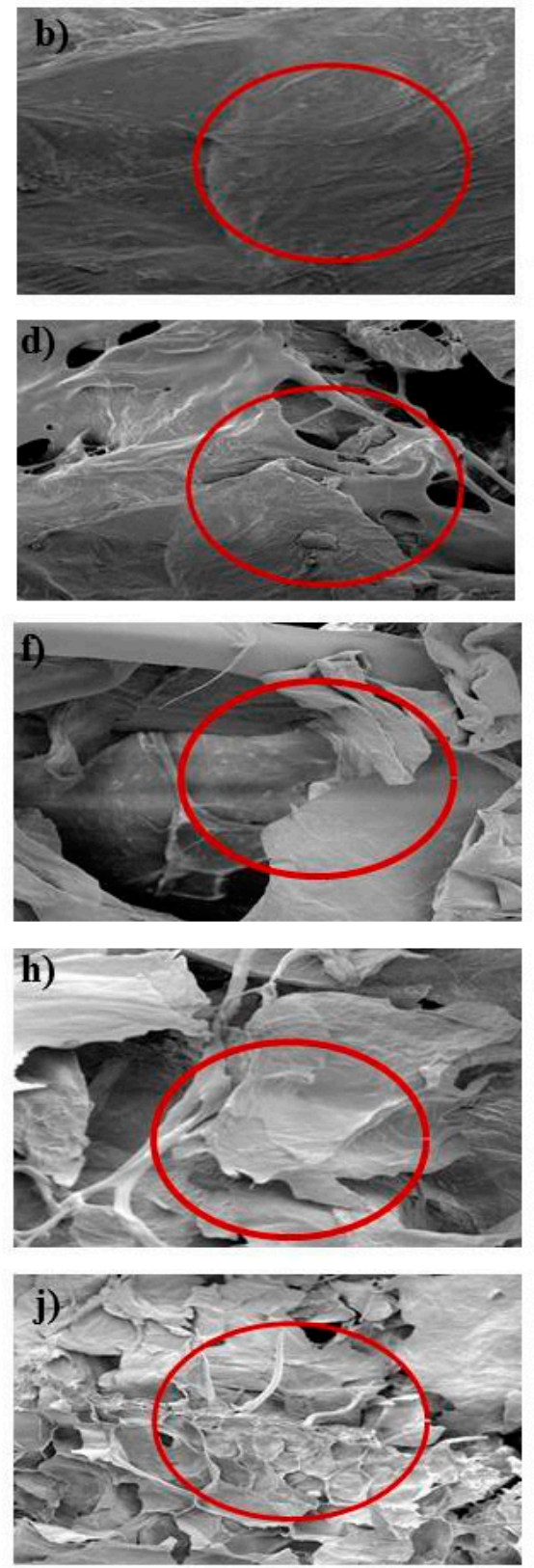

Figure 3. Scanning Electron Microscopy (SEM) of apricot pomace by $70 \times(\mathbf{a}, \mathbf{c}, \mathbf{e}, \mathbf{g}, \mathbf{i})$ and by $575 \times$ $(\mathbf{b}, \mathbf{d}, \mathbf{f}, \mathbf{h}, \mathbf{j}) ;(\mathbf{a}, \mathbf{b})$, untreated, (c,d) solid-liquid, (e,f) ultrasound, (g,h) microwave, and (i,j) infrared. 


\subsection{Antiradical Activity of the Apricot Pomace Extracted by Different Techniques}

Figure 4a shows the inhibition percentage obtained for the four extracts treated by different extraction techniques at their initial polyphenol concentrations. The higher the polyphenols, flavonoids, and tannins contents, the better the antiradical activity (AA) was. This was in concordance with many studies that showed the concentration-dependent antiradical activity of polyphenol extracts [20]. IR extract gave the highest inhibition percentage (40\%) followed by MW (32\%) and US (28\%), and the lowest AA was obtained for the solid-liquid extraction (15\%). On the other hand, and at the same polyphenol concentration (Figure 4b), IR exhibited the best AC than the other extracts. These results could be attributed to the different polyphenol composition, responsible for the enhancement of the radical scavenging activity [21].
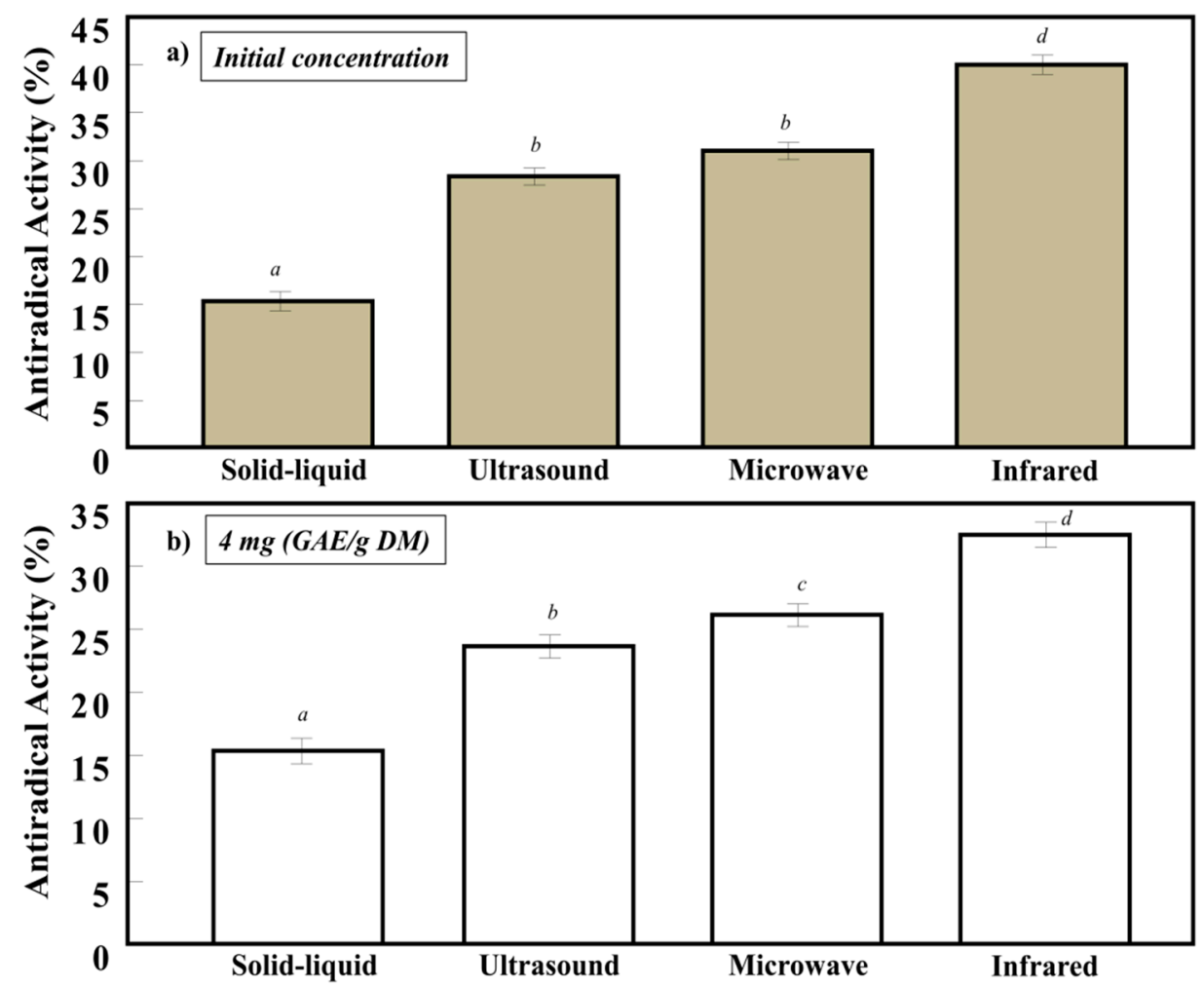

Figure 4. Antiradical scavenging capacity of apricot pomace treated with solid-liquid, ultrasound, microwave, and infrared extracts (a) at their initial concentration and (b) at $4 \mathrm{mg}$ GAE/g DM of polyphenols. Different superscript letters indicate a significant statistical difference $(p<0.05)$.

\subsection{Antimicrobial Activity of the Apricot Pomace Extracted by Different Techniques}

The antimicrobial activities of the four apricot pomace extracts treated by IR, MW, US, and $\mathrm{S} / \mathrm{L}$ techniques were tested against different gram-positive strains and gram-negative bacterial strains (Table 1) using MIC for the different concentrations of $20 \mu \mathrm{g} / \mathrm{mL}, 10 \mu \mathrm{g} / \mathrm{mL}, 5 \mu \mathrm{g} / \mathrm{mL}$, $2.5 \mu \mathrm{g} / \mathrm{mL}$, and $1.25 \mu \mathrm{g} / \mathrm{mL}$. As it was expected, IR extracts of apricot pomace exhibited the lowest inhibitory concentration, denoting the highest inhibitory activity against gram-positive strains and one gram-negative strain. IR extract had also the highest flavonoid and tannin concentrations (Figure $2 b, c$ ), which play an important role in the bioactivity of polyphenols. The antimicrobial results are in concordance with the radical scavenging activity, where the IR extract gave the highest activity (Figure $4 a, b)$. MW and US gave the same results and were active against all the gram-positive bacterial strains (whether they are Methicillin resistant or not) as well as against the gram-negative bacteria (Escherichia coli). However, their required inhibition concentration was more than that of IR. On the other hand, the S/L extract showed the lowest inhibition against two gram-positive coagulase negative 
bacteria since its phenolic content was the smaller compared to the other techniques. These results are in concordance with the findings of Naz et al. (2006), which showed that phenolic molecules have a strong activity against gram-positive strains [22]. The results of Table 1 exhibited that the effectiveness of polyphenols was higher against gram-positive bacterial strains compared to gram-negative ones. Those findings could be due to the fact that polyphenolic compounds have higher activity against gram-positive bacterial strains compared to gram-negative ones, since the latter possess an outer membrane in their cell wall acting as a barrier and consequently decreasing the uptake of these molecules. Moreover, a mutation in porin protein or the efflux phenomena in bacteria could also reduce the activity of polyphenol molecules against them [23,24].

Table 1. Minimum inhibitory concentration $(\mu \mathrm{g} / \mathrm{mL})$ of different gram-positive and gram-negative bacteria obtained with different extraction techniques. (-) indicates the absence of inhibitory effects.

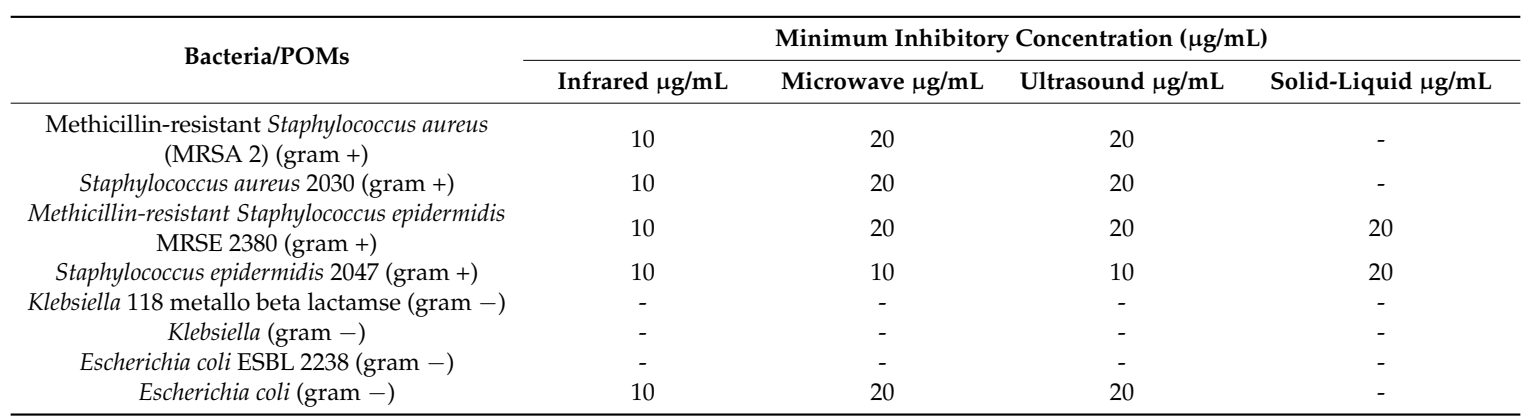

\subsection{Quantification of Polyphenol Extracts by High-Performance Liquid Chromatography}

The composition of polyphenol in apricot pomace extracted by the different techniques was shown in Table 2. The main polyphenols in the extracts were rutin, catechin, and epicatechin (shown also in the supplementary Figure S1). These findings were consistent with the results of Veberic and Stampar (2005) on the polyphenol composition in apricot varieties [25]. Rutin was found in all extracts. However, catechin was detected in IR (3.1 $\mu \mathrm{g} / \mathrm{g}$ DM), MW $(2.1 \mu \mathrm{g} / \mathrm{g}$ DM) and US $(1.5 \mu \mathrm{g} / \mathrm{g}$ DM). Epicatechin was only detected in infrared extract $(4 \mu \mathrm{g} / \mathrm{g} \mathrm{DM})$. Our results are in concordance with the study of Cai et al. (2011), which showed that infrared technique gave higher extraction yields of catechin and epicatechin from grape seeds compared to microwave and ultrasound techniques [16]. The diversity of polyphenol could be related to the structure of the extracted molecules as well as the extraction conditions of each method [16]. IR showed the highest extraction yield for all the detected polyphenol compounds (Table 2). Epicatechin, catechin, and rutin were proven to be strong antioxidant molecules and have a synergistic effect, which contributes to high biological activities [26,27]. This polyphenol diversity could explain the highest biological activity (antiradical and antimicrobial activities) of infrared extract.

Table 2. Polyphenols' composition by High Performance Liquid Chromatography obtained with different extraction techniques. Different superscript letters indicate a significant statistical difference $(p<0.05)$. Nd: Non-detectable.

\begin{tabular}{cccc}
\hline Techniques & Rutin $(\mu \mathrm{g} / \mathrm{g}$ DM) & Catechin $(\mu \mathrm{g} / \mathrm{g}$ DM) & Epicatechin $(\mu \mathrm{g} / \mathrm{g}$ DM) \\
\hline Solid-liquid & $1.6^{\mathrm{a}}$ & $\mathrm{Nd}$ & $\mathrm{Nd}$ \\
Ultrasound & $2.1^{\mathrm{b}}$ & $1.5^{\mathrm{c}}$ & $\mathrm{Nd}$ \\
Microwave & $1.7^{\mathrm{c}}$ & $2.1^{\mathrm{b}}$ & $\mathrm{Nd}$ \\
Infrared & $2.6^{\mathrm{d}}$ & $3.1^{\mathrm{d}}$ & $4^{\mathrm{f}}$ \\
\hline
\end{tabular}

\section{Conclusions}

The comparison of different techniques on the extraction of polyphenols from apricot pomace showed that infrared was the most effective method, which gave the highest polyphenol, flavonoid, and 
tannin concentrations, followed by microwave, ultrasound, and solid-liquid extractions. Infrared has been shown to give the highest antimicrobial and antiradical activity. The scanning electron microscopy revealed that the IR technique induced the highest cellular and structural damage in apricot pomace, which could explain the effectiveness of this novel technique in extracting polyphenols. IR could be considered as a promising technology for food waste recovery.

Supplementary Materials: The following are available online at http://www.mdpi.com/2076-3921/7/12/174/s1, Figure S1: Chromatographic profile of the several phenolic compounds.

Author Contributions: D.C., the main author, is a Ph.D. student at the Faculty of Sciences, Beirut Arab University. D.C. proposed the idea, performed the experiments as well as analyzed the data and wrote the manuscript. N.E.D. is the co-supervisor, who assisted D.C. in the design of the experimental setup, and contributed to the writing and correction of the manuscript. H.N.R. assisted D.C. in the implementation of some experiments and contributed to the correction of the manuscript. I.E.-G. assisted D.C. in the implementation of the antibacterial experiment. N.L. is the main supervisor, who assisted in the development of the proposal and, the design of the experiments, and contributed to writing and correction of the manuscript. R.G.M. initiated the work and contributed to the project design. A.J. and Y.M. contributed to the implementation of the HPLC-DAD Analysis and Scanning electron microscopy parts respectively.

Funding: This research received no external funding.

Conflicts of Interest: The authors declare no conflict of interest. We hereby certify that the work we are submitting is original and that all authors have contributed significantly and are in agreement with the manuscript.

\section{References}

1. Azmir, J.; Zaidul, I.S.M.; Rahman, M.M.; Sharif, K.M.; Mohamed, A.; Sahena, F.; Jahurul, M.H.A.; Ghafoor, K.; Norulaini, N.A.N.; Omar, A.K.M. Techniques for Extraction of Bioactive Compounds from Plant Materials: A Review. J. Food Eng. 2013, 117, 426-436. [CrossRef]

2. Mason, T.J. Ultrasound in synthetic organic chemistry. Chem. Soc. Rev. 2000, 26, 443-451. [CrossRef]

3. Vilkhu, K.; Mawson, R.; Simons, L.; Bates, D. Applications and opportunities for ultrasound assisted extraction in the food industry-A review. Innov. Food Sci. Emerg. Technol. 2008, 9, 161-169. [CrossRef]

4. Wang, Y.; Xi, G.-S.; Zheng, Y.-C.; Miao, F.-S. Microwave-assisted extraction of flavonoids from Chinese herb Radix Puerariae (Ge Gen). J. Med. Plant Res. 2010, 4, 304-308.

5. Gallo, M.; Ferracane, R.; Graziani, G.; Ritieni, A.; Fogliano, V. Microwave assisted extraction of phenolic compounds from four different spices. Molecules 2010, 15, 6365-6374. [CrossRef] [PubMed]

6. Han, Z.P.; Liu, R.L.; Cui, H.Y.; Zhang, Z.Q. Microwave-assisted extraction and LC/MS analysis of phenolic antioxidants in sweet apricot (Prunus armeniaca L.) kernel skins. J. Liq. Chromatogr. Relat. Technol. 2013, 36, 2182-2195.

7. Escobedo, R.; Miranda, R.; Martínez, J. Infrared irradiation: Toward green chemistry, a review. Int. J. Mol. Sci. 2016, 17, 453. [CrossRef] [PubMed]

8. Chen, Y.; Duan, G.; Xie, M.; Chen, B.; Li, Y. Infrared-assisted extraction coupled with high-performance liquid chromatography for simultaneous determination of eight active compounds in Radix Salviae miltiorrhizae. J. Sep. Sci. 2010, 33, 2888-2897. [CrossRef] [PubMed]

9. Madrau, M.A.; Piscopo, A.; Sanguinetti, A.M.; Del Caro, A.; Poiana, M.; Romeo, F.V.; Piga, A. Effect of drying temperature on polyphenolic content and antioxidant activity of apricots. Eur. Food Res. Technol. 2009, 228, 441-448. [CrossRef]

10. Slinkard, K.; Singleton, V. Total phenol analysis: Automation and comparison with manual methods. Am. J. Enol. Vitic. 1977, 28, 49-55.

11. Zhang, D.; Hamauzu, Y. Phenolics, ascorbic acid, carotenoids and antioxidant activity of broccoli and their changes during conventional and microwave cooking. Food Chem. 2004, 88, 503-509. [CrossRef]

12. Ribéreau-Gayon, P.; Dubourdieu, D.; Donèche, B.; Lonvaud, A. Traité d'oenologie-Tome 1 - 6e éd. Microbiologie du vin. Vinifications. Available online: https://www.dunod.com/sciences-techniques / traite-d-oenologie-tome-1-microbiologie-du-vin-vinifications (accessed on 23 October 2018).

13. Michel, T.; Destandau, E.; Elfakir, C. Evaluation of a simple and promising method for extraction of antioxidants from sea buckthorn (Hippophä rhamnoides L.) berries: Pressurised solvent-free microwave assisted extraction. Food Chem. 2011, 126, 1380-1386. [CrossRef] 
14. Vizzotto, M.; Cisneros-zevallos, L.; Byrne, D.H. Large Variation Found in the Phytochemical and Antioxidant Activity of Peach and Plum Germplasm. J. Am. Soc. Hortic. Sci. 2007, 132, 334-340.

15. CLSI. Performance Standards for Antimicrobial Susceptibility Testing; Twenty-Third Informational Supplement (CLSI Document M100-S23). Clinical and Laboratory Standards Institute 33. 2013. Available online: http:/ / reflab.yums.ac.ir/uploads/clsi_m100-s23-2013.pdf (accessed on 23 October 2018).

16. Cai, Y.; Yu, Y.; Duan, G.; Li, Y. Study on infrared-assisted extraction coupled with high performance liquid chromatography (HPLC) for determination of catechin, epicatechin, and procyanidin B2 in grape seeds. Food Chem. 2011, 127, 1872-1877. [CrossRef]

17. Zhang, H.F.; Yang, X.H.; Wang, Y. Microwave assisted extraction of secondary metabolites from plants: Current status and future directions. Trends Food Sci. Technol. 2011, 22, 672-688. [CrossRef]

18. Ferhat, M.A.; Meklati, B.Y.; Smadja, J.; Chemat, F. An improved microwave Clevenger apparatus for distillation of essential oils from orange peel. J. Chromatogr. A 2006, 1112, 121-126. [CrossRef] [PubMed]

19. Dent, M.; Dragović-Uzelac, V.; Garofulić, E.I.; Bosiljkov, T.; Ježek, D.; Brnčić, M. Comparison of Conventional and Ultrasound-assisted Extraction Techniques on Mass Fraction of Phenolic Compounds from Sage (Salvia officinalis L.). Chem. Biochem. Eng. Q. 2015, 29, 475-484. [CrossRef]

20. Rajha, H.N.; Louka, N.; El Darra, N.; Hobaika, Z.; Boussetta, N.; Vorobiev, E.; Maroun, R.G. Multiple Response Optimization of High Temperature, Low Time Aqueous Extraction Process of Phenolic Compounds from Grape Byproducts. Food Nutr. Sci. 2014, 5, 351-360. [CrossRef]

21. Hasmida, M.N.; Nur Syukriah, A.R.; Liza, M.S.; Mohd Azizi, C.Y. Effect of different extraction techniques on total phenolic content and antioxidant activity of quercus infectoria galls. Int. Food Res. J. 2014, 21, 1039-1043.

22. Naz, S.; Ahmad, S.; Ajaz Rasool, S.; Asad Sayeed, S.; Siddiqi, R. Antibacterial activity directed isolation of compounds from Onosma hispidum. Microbiol. Res. 2006, 161, 43-48. [CrossRef] [PubMed]

23. Delcour, A.H. Outer Membrane Permeability and Antibiotic Resistance. Biochim. Biophys. Acta 2009, 1794, 808-816. [CrossRef] [PubMed]

24. Russell, A.D. Similarities and differences in the responses of microorganisms to biocides 1. J. Antimicrob. Chemother. 2003, 52, 750-763. [CrossRef] [PubMed]

25. Veberic, R.; Stampar, F. Selected polyphenols in fruits of different cultivars of genus Prunus. Phyt. Ann. Rei Bot. 2005, 45, 375-383.

26. Sun, T.; Ho, C.T. Antioxidant activities of buckwheat extracts. Food Chem. 2005, 90, 743-749. [CrossRef]

27. Maier, T.; Schieber, A.; Kammerer, D.R.; Carle, R. Residues of grape (Vitis vinifera L.) seed oil production as a valuable source of phenolic antioxidants. Food Chem. 2009, 112, 551-559. [CrossRef] 